JOTE Volume 2 Nomor 1 Tahun 2020 Halaman 118-124 JOURNAL ON TEACHER EDUCATION

Research \& Learning in Faculty of Education

\title{
MENINGKATKAN AKTIVITAS SISWADALAM PEMBELAJARAN PKn MENGGUNAKAN MODEL PEMBELAJARAN KOOPERATIF TIPE STAD DI KELAS X SMK NEGERI 2 MAUMERE
}

\author{
Beata Eka Purwanti \\ Guru PKn di SMK Negeri 2 Maumere, Sikka, NTT \\ Email : beataeka00@gmail.com
}

\begin{abstract}
Abstrak
Tujuan penelitian ini adalah untuk meningkatkan aktivitas siswa dalam pembelajaran PKn dengan menggunakan model pembelajaran Kooperatif Tipe STAD di Kelas X SMK Negeri 2 Maumere. Penelitian ini merupakan penelitian tindakan kelas, metode yang digunakan dalam penelitian ini adalah metode penelitian deskriptif dengan menggunakan jenis data kualitatif dengan penganalisaan data secara kuantitatif. melalui langkah-langkah pengumpulan, pengolahan, penganalisaan, dan penyajian data dengan jumlah subjek penelitian 20 siswa. Adapun pelaksanaannya yakni mengunakan model pembelajaran kooperatif tipe STAD yang melalui empat tahap yakni (1) perencanaan, (2) pelaksanaan tindakan, (3) observasi dan (4) refleksi. Hasil penelitian menunjukkan aktivitas siswa dalam pembelajaran pada siklus pertama dengan memperoleh nilai rata-rata aktivitas siswa 80 dengan kriteria cukup dan ada peningkatan pada siklus kedua dengan perolehan nilai rata-rata aktivitas siswa 88 dengan kriteria baik, sehingga model pembelajaran kooperatif tipe STAD dinyatakan dapat meningkatkan aktivitas siswa dalam pembelajaran PKn.
\end{abstract}

Kata kunci: Menulis karangan argumentasi, Metode Problem Based Learning.

\begin{abstract}
The purpose of this study was to increase student activity in Civics learning by using the STAD Type Cooperative learning model in Class X SMK Negeri 2 Maumere. This research is a classroom action research, the method used in this research is descriptive research method using qualitative data types with quantitative data analysis. through the steps of collecting, processing, analyzing, and presenting data with the number of research subjects 20 students. The implementation is using the STAD type cooperative learning model which goes through four stages, namely (1) planning, (2) implementing actions, (3) observation and (4) reflection. The results showed that student activity in learning in the first cycle was obtained by obtaining an average value of 80 student activity with sufficient criteria and there was an increase in the second cycle with the acquisition of an average value of 88 student activity with good criteria, so that the STAD type cooperative learning model was declared to improve student activities in civics learning.
\end{abstract}

Keywords: Writing arguments, Problem Based Learning Method. 


\section{PENDAHULUAN}

Negara berkembang selalu berusaha untuk mengejar ketinggalannya, yaitu dengan giat melakukan pembangunan di segala bidang kehidupan. Dalam bidang pendidikan pemerintah selalu berusaha untuk meningkatkan kualitas pendidikan dengan berbagai cara seperti mengganti kurikulum, meningkatkan kualitas guru melalui penataran-penataran atau melanjutkan sekolah ke tingkat yang lebih tinggi, memberi dana Bantuan Operasional Sekolah (BOS) dan sebagainya.

Sesuai dengan UU No. 20 tahun 2003 Tentang Sistem Pendidikan Nasional, Pasal 3 menyatakan bahwa; "Pendidikan nasional berfungsi mengembangkan kemampuan dan membentuk watak serta peradaban bangsa yang bermartabat dalam rangka mencerdaskan kehidupan bangsa, bertujuan untuk berkembangnya potensi peserta didik agar menjadi manusia yang bertakwa kepada Tuhan Yang Maha Esa, berakhlak mulia, sehat, berilmu, cakap, kreatif, mandiri dan menjadi warga negara yang demokratis serta bertanggung jawab". Dengan memperhatikan isi dari UU No. 20 Tahun 2003 tersebut, peneliti berpendapat bahwa tugas seorang guru memang berat, sebab kemajuan suatu bangsa ditentukan oleh keberhasilan pendidikan dari bangsa itu sendiri.

Sesuai dengan Depdiknas (2005:33) yang menyatakan bahwa, "Pendidikan Kewarganegaraan adalah mata pelajaran yang memfokuskan pada pembentukan diri yang beragam dari segi agama, sosio-kultural, bahasa, usia, suku bangsa untuk menjadi warga negara yang cerdas, terampil, dan berkarakter yang dilandasi oleh Pancasila dan UUD 1945". Untuk mencapai tujuan ini peranan guru sangat menentukan.Peran guru adalah: "Sebagai sumber belajar, fasilitator, pengelola, demonstrator, pembimbing, dan evaluator". Sebagai motivator guru harus mampu membangkitkan motivasi siswa agar aktivitas siswa dalam proses pembelajaran berhasil denganbaik.

Salah satu cara untuk membangkitkan aktivitas siswa dalam proses pembelajaran adalah dengan mengembangkan model pembelajaran yang selama ini kurang diminati oleh siswa sehingga membuat siswa jenuh dan tidak kreatif. Suasana belajar mengajar yang diharapkan adalah menjadikan siswa sebagai subjek yang berupaya menggali sendiri, memecahkan sendiri masalahmasalah dari suatu konsep yang dipelajari, sedangkan guru lebih banyak bertindak sebagai motivator danfasilitator. Situasi belajar yang diharapkan di sini adalah siswa yang lebih banyak berperan (kreatif).

Berdasarkan hasil observasi di SMK Negeri 2 Maumere, pembelajaran PKn masih sering menggunakan metode pembelajaran ceramah. Metode pembelajaran ini kurang membangkitkan aktivitas siswa dalam belajar. Hal ini tampak dari perilaku siswa yang cenderung hanya mendengar dan mencatat pelajaran yang diberikan guru. Berdasarkan hal tersebut, maka peneliti akan mencoba menggunakan model pembelajaran lain yaitu model pembelajaran koperatif tipe STAD. Keunggulan dari metode pembelajaran kooperatif tipe STAD adalah adanya kerja sama dalam kelompok dan dalam menentukan keberhasilan kelompok tergantung keberhasilan individu, sehingga setiap anggota kelompok tidak bisa menggantungkan pada anggota yang lain. Pembelajaran kooperatif 
tipe STAD menekankan pada aktivitas dan interaksi diantara siswa untuk saling memotivasi saling membantu dalam menguasai materi pelajaran guna mencapai prestasi yang maksimal.

Model pembelajaran kooperatif tipe STAD sangat tepat untuk diterapkan pada pembelajaran $\mathrm{PKn}$, sebab pembelajaran $\mathrm{PKn}$ memerlukan banyak pengkajian melalui diskusi yang dapat dilakukan melalui kelompok belajar. Ketertarikan peneliti mengambil model pembelajaran kooperatif tipe STAD, dalam model pembelajaran kooperatif tipe STAD semua anggota kelompok diberi tugas dan tanggung jawab, baik individu maupun kelompok. Oleh sebab itu, dalam penelitian ini peneliti mengambil sebuah judul yaitu: "Meningkatan Aktivitas Siswa dalam Pembelajaran PKn dengan Menggunakan Model Pembelajaran Kooperatif Tipe STAD di Kelas X SMK Negeri 2 Maumere".

\section{METODE}

\section{RancanganPenelitian}

Sesuai dengan masalah yang diteliti, maka jenis penelitian yang dilakukan oleh peneliti berupa Penelitian Tindakan Kelas (PTK), yaitu suatu kegiatan penelitian yang dilakukan di kelas dalam arti luas. Penelitian tindakan kelas ini berisi pra tindakan dan tindak lanjut. Pada pra tindakan berisi renungan dalam mengajar sehingga dapat menemukan kelemahan-kelemahan, kekurangan dalam pembelajaran menulis kreatif kemudian dilakukan dengan tindakan, tindak lanjut yang dapat digunakan untuk memecahkan masalah dalam pembelajaran.

Penelitian tindakan kelas (PTK), dilaksanakan dalam bentuk proses pengkajian berdaur yang terdiri atas empat tahap yaitu: Perencanaan (planning), tindakan (action), pengamatan (observation), dan refleksi (reflection).

Tahapan pelaksanaan penelitian tindakan kelas ini mengacu pada desain yang dikemukakan oleh Kemmis dan McTaggart ${ }^{5}$, yaitu sebagai berikut:

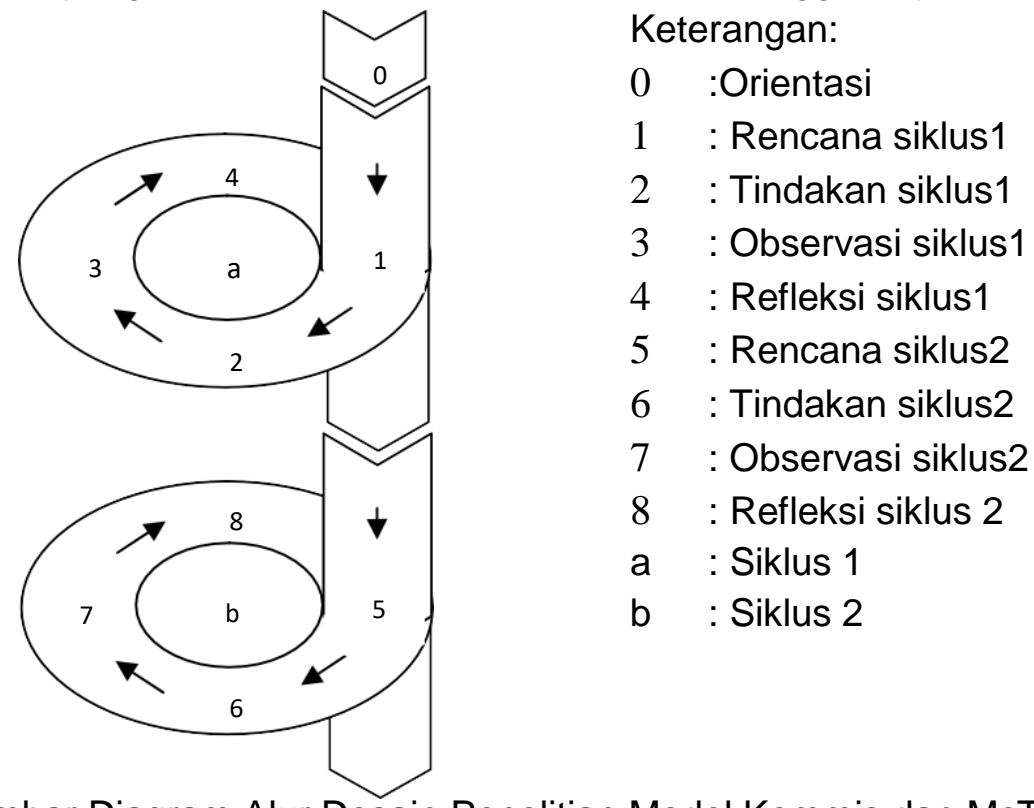

Gambar Diagram Alur Desain Penelitian Model Kemmis dan McTaggart. 
Tindakan atau pelaksanaan merupakan apa yang akan dilakukan peneliti sebagai upaya perbaikan dan peningkatan. Dalam hal ini, upaya perbaikan terhadap siswa tentang kesalahan-kesalahan siswa. Observasi atau pengamatan, yaitu mengamati hasil dari tindakan yang dilakukan penulis terhadap siswa. Kesalahan siswa, kesulitan siswa, dan tanggapan siswa dijadikan pertimbangan untuk perencanaan siklus berikutnya.

Refleksi yaitu tindakan mengkaji, melihat, dan mempertimbangkan hasil atau dampak tindakan dari berbagai kriteria. Berdasarkan refleksi tersebut, penulis bersama-sama guru lain dapat melakukan revisi, perbaikan, terhadap awal untuk rencana berikutnya.

\section{Subyek Penelitian}

Penelitian ini dilaksanakan di SMK Negeri 2 Maumere pada siswa kelas $X$ dengan jumlah siswa 20 orang.

\section{Instrumen Penelitian}

Observasi guru

Observasi guru dilakukan dengan tujuan untuk mengetahui bagaimana aktivitas guru dalam proses pembelajaran dengan menggunakan model pembelajaran Kooperatif tipe STAD. Adapun aspek yang diamati meliputi: Langkah pembelajaran dan keaktifan guru dalam pembelajaran

Observasi siswa

Observasi atau pengamatan yang dilakukan pada siswa dengan tujuan untuk mengetahui aktivitas siswa dalam pembelajaran dengan model pembelajaran kooperatif tipe STAD yang dilakukan oleh guru. Adapun aspek yang diamati meliputi: respon siswa dalam menerima informasi dari guru, mengajukan pertanyaan, menjawab pertanyaan siswa maupun guru, memberi saran, mengemukakan pendapat, menyelesaikan tugas kelompok, mempresentasikan hasil kerja kelompok.

\section{HASIL DAN PEMBAHASAN}

Pelaksanaan Tindakan Siklus Pertama

Data Hasil Observasi Guru SiklusPertama

Berdasarkan hasil observasi aktivitas guru dapat diperoleh gambaran tentang kemampuan guru (peneliti) yang akan melakukan proses meningkatkan aktivitas siswa dalam pembelajaran PKn melalui model pembelajaran kooperatif tipe STAD di kelas X SMK Negeri 2 Maumere. Hal ini bisa dikatakan dari 11 komponen yang diamati tidak satupun yang dinilai kurang, sementara yang mendapatkan penilaian cukup 6 , dan penilaian baik 5. Dengan melihat penilaian beberapa komponen tersebut dapat diketahui bahwa proses pembelajaran untuk meningkatkan aktivitas siswa dalam pembelajaran PKn melalui model pembelajaran kooperatif tipe STAD di kelas X SMK Negeri 2 Maumere yang dilakukan oleh guru (peneliti) mendapatkan penilaian cukup.

\section{Data hasil observasi aktivitas siswa siklus pertama}

Aktivitas siswa dalam pembelajaran PKn akan berpengaruh terhadap hasil belajar siswa. Oleh karena itu, peneliti melakukan observasi aktivitas siswa 
dalam pembelajaran PKn ketika diterapkan model pembelajaran kooperatif tipe STAD di kelas X SMK Negeri 2 Maumere.

Berdasarkan nilai rata-rata aktivitas belajar siswa dalam pembelajaran PKn melalui model pembelajaran kooperatif tipe STAD di kelas X SMK Negeri 2 Maumere yang diperoleh siswa yaitu 80 dengan demikian aktivitas belajar siswa dalam pembelajaran PKnmelaluimodel pembelajaran kooperatif tipe STAD di kelas X SMK Negeri 2 Maumere pada siklus pertama dapat dikatakan belum meningkat.

Berdasarkan hasil pengkajian dapat dilihat bahwa siswa yang memperoleh skor $<74$ (kurang) dengan persentase 5\%, skor 75-84 (cukup) dengan persentase 55\%, skor 85-94 (baik) dengan persentase 40\%, dan skor 95 - 100 (sangat baik) tidak ada. Dengan demikian, aktivitas siswa dalam pembelajaran PKn melalui model pembelajaran kooperatif tipe STAD di kelas $X$ SMK Negeri 2 Maumere mencapai nilai rata-rata 80 dengan kriteria cukup dan dinyatakan peningkatan aktivitas siswa dalam pembelajaran PKn melalui model pembelajaran kooperatif tipe STAD di kelas X SMK Negeri 2 Maumere belum berhasil sehingga harus dilanjutkan pada siklus kedua

\section{Pelaksaan Tindakan Siklus Kedua Data Hasil Observasi Guru SiklusKedua}

Berdasarkan hasil observasi aktivitas guru siklus kedua, dapat diperoleh gambaran tentang kemampuan guru (peneliti) yang akan melakukan proses meningkatkan aktivitas siswa dalam pembelajaran PKn melalui model pembelajaran kooperatif tipe STAD di kelas X SMK Negeri 2 Maumere pada siklus kedua. Hal ini bisa dikatakan dari 11 komponen yang diamati tidak satupun yang dinilai kurang dan cukup, sementara penilaian baik 6 , dan penilaian sangat baik 5 . Dengan melihat penilaian beberapa komponen tersebut dapat diketahui bahwa proses pembelajaran untuk meningkatkan aktivitas siswa dalam pembelajaran PKn melalui model pembelajaran kooperatif tipe STAD di kelas $X$ SMK Negeri 2 Maumere yang dilakukan oleh guru (peneliti) pada siklus kedua mendapatkan penilaianbaik.

Berdasarkan hasil observasi guru (peneliti) adalah 3,4 dan dibulatkan menjadi 3, maka dapat disimpulkan kegiatan guru (peneliti) dalam melakukan perencanaan dan tindakan pada proses meningkatkan aktivitas siswa dalam pembelajaran PKn melalui model pembelajaran kooperatif tipe STAD di kelas X SMK Negeri 2 Maumere siklus kedua memperoleh hasil baik dan dinyatakan dapat meningkatkan aktivitas siswa.

Berdasarkan hasil observasi aktivitas siswa dalam pembelajaran PKn melalui model pembelajaran kooperatif tipe STAD di kelas X SMK Negeri 2 Maumere pada siklus kedua diperoleh nilai rata-rata aktivitas siswa yaitu 88 . Dengan demikian aktivitas siswa dalam pembelajaran PKn melalui model pembelajaran kooperatif tipe STAD di kelas X SMK Negeri 2 Maumere pada siklus kedua dapat ditingkatkan sudah meningkat. 


\section{SIMPULAN}

Berdasarkan hasil penelitian yang dilakukan dapat ditarik kesimpulan yaitu Penerapan model pembelajaran kooperatif tipe STAD dapat meningkatkan aktivitas belajar siswa dan dapat mengoptimalkan peran siswa dalam berinteraksi dengan siswa lain maupun dengan guru. Siswa juga dapat berkomunikasi secara ilmiah dalam suatu kegiatan diskusikelompok.

\section{DAFTAR PUSTAKA}

Depdiknas, 2005, Pendidikan Kewarganegaraan, Kurikulum dan Silabus Pendidikan Kewarganegaraan, Jakarta : Depdiknas

Nurkancana, W. dan Sumartana, P.P.N. (1986). Evaluasi Pendidikan. Surabaya: Usaha Nasional.

Undang-undang Republik Indonesia No. 20 tahun 2003 Tentang Sistem Pendidikan Nasional, 2003, Jakarta : Depdiknas

Wina Sanjaya, 2006, Strategi Pembelajaran Berorientasi Proses Standar Proses Pendidikan, Jakarta : Kencana Prima

Wiriatmadja,Rochati, 2005, Metode Penelitian Tindakan Kelas, Bandung : Rosdakarya

Arikunto, S dkk. 2006. Prosedur Penelitian suatu Pendekatan Praktik (Edisi Revisi V). Jakarta: Asdi Mahasatya.

Mansur, S. 2018. Aplikasi Asesmen Dalam Pembelajaran IPA di Kelas IV Sekolah Dasar Negeri Gelogor. Universitas Muhammadiyah Makasar. Jurnal Riset Pendidikan Dasar. 1 (1): 49-55. DOI: http://dx.doi.org/10.26618/irpd.v1i1.1239

Mansur, S. 2018. Penerapan Model Pembelajaran Kooperatif Tipe STAD untuk Meningkatkan Motivasi dan Hasil Belajar pada Konsep Ekosistem di SMA Negeri 2 Maumere. STAI Darul Kamal NW Kembang kerang. Jurnal Al-Muta'aliyah. 1 (1): 117-127. DOI: http://ejournal.kopertais4.or.id/sasambo/index.php/mutaaliyah

Mansur, S (2018). Pengaruh Pendekatan Jelajah Alam Sekitar (JAS) Terhadap Hasil Belajar Siswa pada Materi Klasifikasi Mahluk Hidup di SMPK Binawirawan Maumere. BIOEDUSCIENCE: Jurnal Pendidikan Biologi Dan Sains, 2(1), 74-80. https://doi.org/10.29405/j.bes/2174-801314

Mansur S, Bare. Y. (2019) Meningkatkan Hasil Belajar Siswa pada Konsep Perubahan dan Pelestarian Lingkungan Hidup dengan Model Discovery Learning di SMAS Katolik ST Gabriel Maumere, BIOEDUSCIENCE: Jurnal Pendidikan Biologi dan Sains: Vol. 3 No. 2 
Nafia, I. 2013. Meningkatan Aktivitas dan hasil belajar mengelola konflik dengan CO-OP siswa $X \quad$ BB2(online). (http://www.slametpriyadi.com/2011 /09/19/kelebihan-keku-ranganmetode-ceramah-dalam pembelajaran/, Diakses 21 april 2019).

Rofiq, M. N. 2010. Pembelajaran Koperatif dalam Pengajaran Islam. Jurnal FALASIFA vol. 1 No. 1 Maret 2010.

Rusman. 2012. Model-Model Pembelajaran. EdisiKedua. Rajagrafindo Persada: Jakarta.

Slavin, R E. 2007. Cooperative Learning Teotri, Riset dan Praktek. Bandung: Nusa Media. 